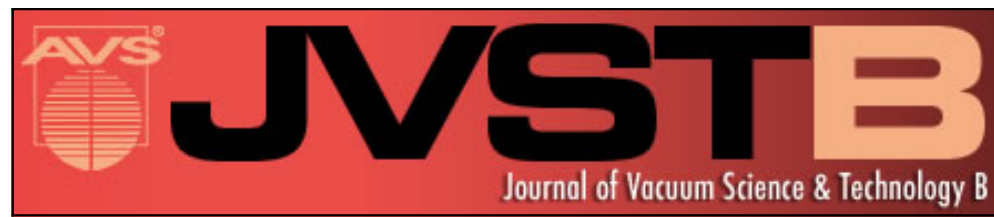

\title{
Electromigration behavior of Cu metallization interfacing with Ta versus TaN at high temperatures
}

Shabnam Mardani, Hans Norström, Ulf Smith, Fredrik Gustavsson, Jörgen Olsson, and Shi-Li Zhang

Citation: Journal of Vacuum Science \& Technology B 34, 060603 (2016); doi: 10.1116/1.4967372

View online: http://dx.doi.org/10.1116/1.4967372

View Table of Contents: http://scitation.aip.org/content/avs/journal/jvstb/34/6?ver=pdfcov

Published by the AVS: Science \& Technology of Materials, Interfaces, and Processing

\section{Articles you may be interested in}

High-temperature Ta diffusion in the grain boundary of thin $\mathrm{Cu}$ films

J. Vac. Sci. Technol. B 34, 040606 (2016); 10.1116/1.4950744

Suppression of native oxide growth in sputtered TaN films and its application to Cu electroless plating J. Appl. Phys. 94, 4697 (2003); 10.1063/1.1609644

Characteristics of copper films deposited on $\mathrm{H} 2$-plasma-treated TaN substrate by chemical vapor deposition J. Vac. Sci. Technol. B 20, 1947 (2002); 10.1116/1.1502697

Interfacial mechanism studies of electroless plated Cu films on a -Ta:N layers catalyzed by PIII J. Vac. Sci. Technol. A 20, 733 (2002); 10.1116/1.1465448

Microtexture and electromigration-induced drift in electroplated damascene $\mathrm{Cu}$ J. Appl. Phys. 87, 2792 (2000); 10.1063/1.372258

\section{Instruments for Advanced Science}

Contact Hiden Analytical for further details: w www.HidenAnalytical.com E info@hiden.co.uk CLICK TO VIEW our product catalogue

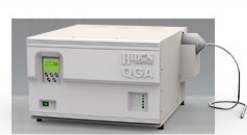

Gas Analysis

, dynamic measurement of reaction gas streams catalysis and thermal analysis , molecular beam studies

'dissolved species probes

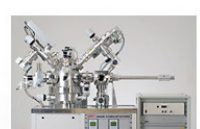

Surface Science

, UHVTPD

SIMS elemental imaging - surface mapping

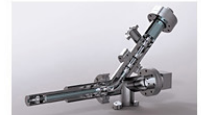

Plasma Diagnostics

, plasma source characterization etch and deposition process rection kinetic studies , analysis of neutral and radical species

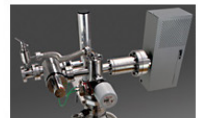

Vacuum Analysis ' partial pressure measurement and control of process gases reactive sputter process control vacuum diagnostics vacuum coating process monitoring 


\title{
Electromigration behavior of Cu metallization interfacing with Ta versus TaN at high temperatures
}

\author{
Shabnam Mardani, Hans Norström, Ulf Smith, Fredrik Gustavsson, Jörgen Olsson, \\ and Shi-Li Zhang a) \\ Solid State Electronics, The Angström Laboratory, Uppsala University, 75121 Uppsala, Sweden
}

(Received 25 August 2016; accepted 27 October 2016; published 8 November 2016)

\begin{abstract}
High-temperature stability of Cu-based interconnects is of technological importance for electronic circuits based on wide band gap semiconductors. In this study, different metal stack combinations using $\mathrm{Ta}$ or $\mathrm{TaN}$ as capping- and/or barrier-layer, in the configuration cap/Cu/barrier, are evaluated electrically and morphologically prior to and after high-temperature treatments. The symmetric combinations $\mathrm{Ta} / \mathrm{Cu} / \mathrm{Ta}$ and $\mathrm{TaN} / \mathrm{Cu} / \mathrm{TaN}$ are characterized by a low and stable sheet resistance after annealing up to $700{ }^{\circ} \mathrm{C}$. Asymmetric combinations of $\mathrm{Ta} / \mathrm{Cu} / \mathrm{TaN}$ and $\mathrm{TaN} / \mathrm{Cu} / \mathrm{Ta}$, however, display an increase in sheet resistance values after annealing at $500^{\circ} \mathrm{C}$ and above. This increase in sheet resistance is considered to result from Ta diffusion into the grain boundaries of the $\mathrm{Cu}$ film. The preliminary electromigration studies on the $\mathrm{TaN} / \mathrm{Cu} / \mathrm{Ta}$ and $\mathrm{TaN} / \mathrm{Cu} / \mathrm{TaN}$ structures show a twofold higher activation energy and a tenfold longer lifetime for the former, thus suggesting an important role of the interface between $\mathrm{Cu}$ and the cap and/or barrier. (C) 2016 American Vacuum Society. [http://dx.doi.org/10.1116/1.4967372]
\end{abstract}

\section{INTRODUCTION}

High-temperature electrical and morphological stability of interconnect is critical for electronic systems based on wide band gap semiconductors. In this context, $\mathrm{Cu}$ is found to have several interesting properties, including low resistivity and high resistance to electromigration in comparison with $\mathrm{Al} .{ }^{1-3} \mathrm{As} \mathrm{Cu}$ metallization is well-studied as the dominant interconnect in advanced integrated circuits (ICs), it is a good choice to start with by examining its applicability for high-temperature applications. We have, therefore, investigated the thermal stability of various metal stacks with $\mathrm{Cu}$ films having Ta and TaN layers as diffusion barrier and/or as surface capping layers at temperatures from 400 to $700^{\circ} \mathrm{C} .{ }^{4}$ Two distinct systems have been studied: asymmetric with $\mathrm{Ta}$ on one side and $\mathrm{TaN}$ on the other, and symmetric with either $\mathrm{Ta}$ or $\mathrm{TaN}$ on both sides. For the asymmetric systems, we have found that $\mathrm{Ta}$ is released from the Ta layer and moves through the $\mathrm{Cu}$ film to react with the TaN layer at the opposite interface via the $\mathrm{Cu}$ grain boundaries (GBs) after annealing at $500{ }^{\circ} \mathrm{C}$ or above..$^{4,5}$ Without a capping layer, Ta is also released from the Ta barrier layer and diffuses up to the $\mathrm{Cu}$ surface, most likely driven by oxidation of $\mathrm{Ta}$ and surface passivation of $\mathrm{Cu}$ by Ta. ${ }^{4,5}$ For the symmetric systems, no Ta diffusion could be inferred from sheet resistance measurement. ${ }^{4}$ Since Ta cannot be released from the stable TaN, the $\mathrm{Cu} / \mathrm{TaN}$ interface would stay intact after annealing. This was confirmed with samples of $\mathrm{Cu}$ on TaN without any capping layer. ${ }^{4,5}$ For Ta on both sides of the $\mathrm{Cu}$ film, lack of a driving force could explain the absence of Ta diffusion. Instead, protrusion of $\mathrm{Ta}$ into $\mathrm{Cu}$ was found to occur at $600{ }^{\circ} \mathrm{C}$ and above by means of cross-sectional transmission electron microscopy (TEM) ${ }^{6}$

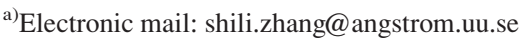

Electromigration (EM) represents a critical reliability issue important for any integrated device or circuit. Electromigration may cause instability in, and eventually failure of, the interconnects. It usually involves complex failure mechanisms. ${ }^{1-3,7}$ Defect formation and evolution under high-current density stressing is an essential factor. Electromigration in $\mathrm{Cu}$ interconnect formed according to the damascene concept has been extensively studied and is well documented in the literature. ${ }^{8}$ But less information is available regarding the role of the commonly used $\mathrm{TaN}$ and $\mathrm{Ta}$ liner materials when it comes to integrity and reliability of the $\mathrm{Cu}$ interconnect. ${ }^{9,10}$ The purpose of this work is to elucidate the pros and cons of $\mathrm{Cu}$ films stacked by these materials with respect to resistance to EM and electrical integrity at elevated temperatures. In order to shed some light on the role of interfaces, we focus on both symmetrically and asymmetrically layered systems, i.e., $\mathrm{TaN} / \mathrm{Cu} / \mathrm{TaN}$ and $\mathrm{TaN} / \mathrm{Cu}$ / $\mathrm{Ta}$, respectively. In the symmetric case, the possible presence of $\mathrm{Ta}$ in the $\mathrm{Cu}$ GBs and at the interfaces is avoided. Our results show that the latter stack with $\mathrm{Ta}$ as a barrier is more robust in resisting EM. This improvement is inferred to be the result of Ta diffusion into and through the $\mathrm{Cu}$ film up to the $\mathrm{Cu}-\mathrm{TaN}$ interface. Our findings indicate that the choice of barrier has a strong impact on the reliability of the $\mathrm{Cu}$ interconnect.

\section{EXPERIMENT}

Two sets of samples were prepared, both employing blanket, (100)-oriented, p-type Si wafers with a $550 \mathrm{~nm}$ thick thermally grown $\mathrm{SiO}_{2}$ film as the substrate. For material studies, four different metal stacks were deposited consecutively without breaking vacuum in a pulsed-DC mode Von Ardenne sputter system. They shared the same layer configuration with a $100 \mathrm{~nm} \mathrm{Cu}$ film sandwiched between a $50 \mathrm{~nm}$ $\mathrm{Ta}$ or TaN barrier layer and a $50 \mathrm{~nm} \mathrm{Ta}$ or TaN capping 
layer. The base pressure in the deposition chamber was below $10^{-4} \mathrm{~Pa}$. To investigate the relation between thermal and electrical stability, samples were annealed in a vacuum chamber with the base pressure below $1.3 \times 10^{-5} \mathrm{~Pa}$. Samples were annealed from 400 to $800^{\circ} \mathrm{C}$, each temperature for $60 \mathrm{~min}$. The composition, thicknesses, and interfacial reactions of as-deposited and the subsequently annealed samples were characterized by means of Rutherford backscattering spectrometry (RBS) with $2 \mathrm{MeV} \mathrm{He}$ ions at a backscattering angle of $170^{\circ}$. Cross-sections of the asdeposited and annealed samples were studied using TEM. Sheet resistance was measured using a four-point probe as a first attempt to survey possible reactions involving $\mathrm{Cu}$.

For the EM test structures, each configured as a standard four-terminal resistor, two metal stacks $\mathrm{TaN} / \mathrm{Cu} / \mathrm{Ta}$ and $\mathrm{TaN} / \mathrm{Cu} / \mathrm{TaN}$ were deposited with the aforementioned parameters. The barrier ( $\mathrm{Ta}$ or $\mathrm{TaN})$ and cap (TaN) layers were $50 \mathrm{~nm}$ thick and the $\mathrm{Cu}$ films $300 \mathrm{~nm}$. The test structures were patterned by ion milling in combination with photolithography. The designed resistor line widths ranged from 2 to $20 \mu \mathrm{m}$ while the lengths varied from 200 to $800 \mu \mathrm{m}$. Both patterned metal stacks were annealed at $600{ }^{\circ} \mathrm{C}$ for $60 \mathrm{~min}$ in a vacuum furnace. Unannealed structures were kept as references. Finally, the structures were passivated with a $200 \mathrm{~nm}$ thick $\operatorname{SiN}_{\mathrm{x}}$ layer prepared by means of plasma-enhanced chemical vapor deposition (PECVD) at $300^{\circ} \mathrm{C}$. Contact openings, $200 \times 200 \mu \mathrm{m}$ in size, were lithographically defined and dry-etched. In the openings, a Pd layer, approximately $500 \mathrm{~nm}$ thick, was subsequently deposited on the TaN surface by means of evaporation. The contact pads were defined by lift-off technique. Variation of the resistance of the resistors was measured under thermal and electrical stresses on a probe-station (Karl Süss PM8) equipped with a hot-chuck (Temptronic TP0315). This was performed using an HP 4142B parameter analyzer equipped with a high power (current-voltage) module 41420A. The system was controlled by a PC using METRICS ICS software. Failed $\mathrm{Cu}$ interconnect wires, as a result of EM, were inspected using scanning electron microscope (SEM).

\section{RESULTS AND DISCUSSION}

The experimental results will be presented in two separate subsections. Variation in sheet resistance, $R_{\mathrm{s}}$, of the four blanket layer stacks with temperature is first analyzed with the support of microscopic and spectrometric data for interface morphology. Attention is then directed to the patterned test structures for the EM performance of the layer stacks in real-time at elevated temperatures.

\section{A. High-temperature behavior of the metal stacks}

The measured $R_{\mathrm{s}}$ for the four blanket metal stacks is plotted in Fig. 1(a) at different annealing temperatures. The thinner $\mathrm{Cu}$ films of $100 \mathrm{~nm}$ thickness, instead of $300 \mathrm{~nm}$, facilitated analysis and interpretation of Ta diffusion across the $\mathrm{Cu}$ films based on RBS and $R_{\mathrm{S}}$ data. ${ }^{3}$ It is found that $R_{\mathrm{S}}$ for all samples first decreases with increasing annealing temperature up to $400-500{ }^{\circ} \mathrm{C}$ due to grain growth of $\mathrm{Cu} .^{5}$ Further increase in temperature above $600{ }^{\circ} \mathrm{C}$ shows an appreciable increase in $R_{\mathrm{S}}$ by up to $20 \%-30 \%$ for the asymmetric combinations $\mathrm{Ta} / \mathrm{Cu} / \mathrm{TaN}$ and $\mathrm{TaN} / \mathrm{Cu} / \mathrm{Ta}$. In contrast, only small changes in $R_{\mathrm{s}}$ are evident for the symmetric combinations $\mathrm{Ta} / \mathrm{Cu} / \mathrm{Ta}$ and $\mathrm{TaN} / \mathrm{Cu} / \mathrm{TaN}$ even after annealing at $800^{\circ} \mathrm{C}$. Our previous results indicate a massive Ta transport
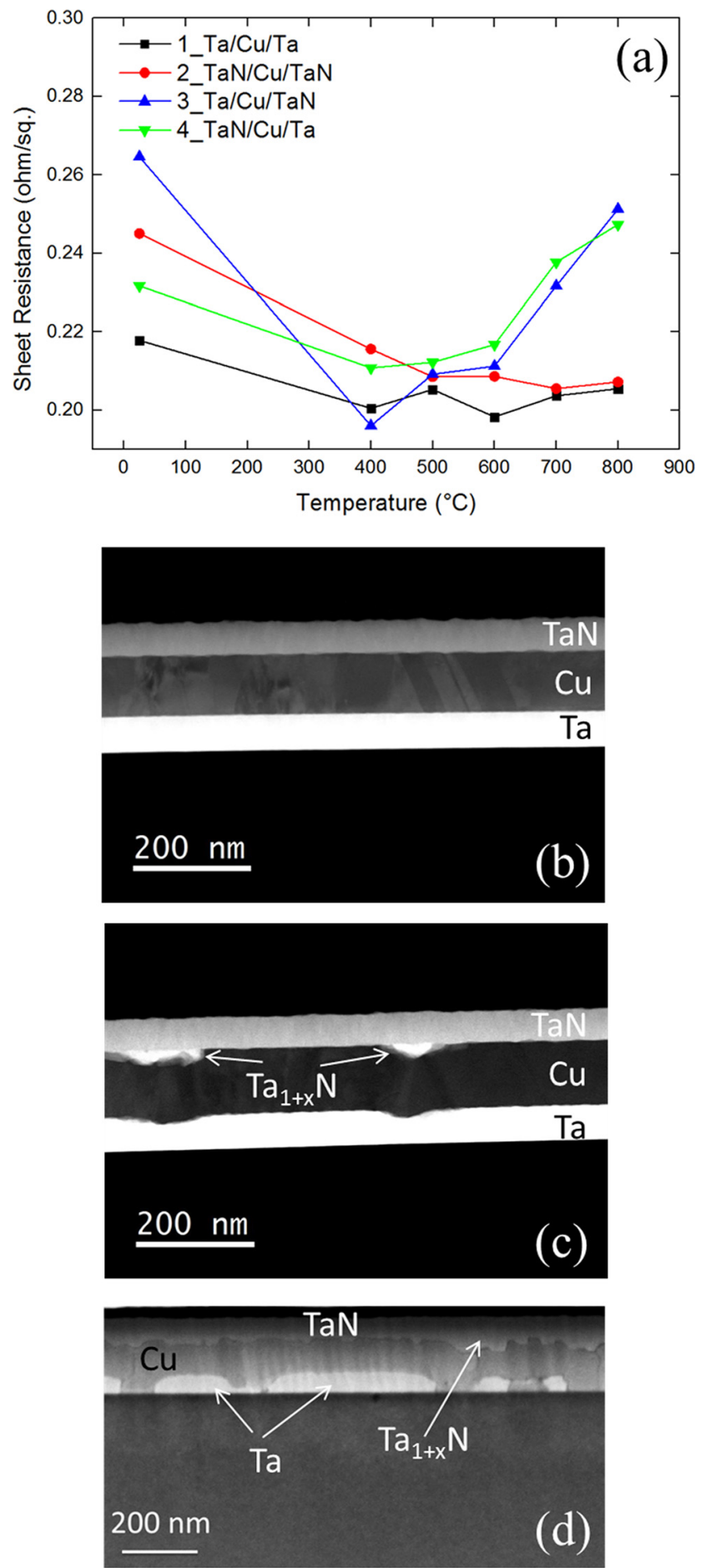

FIG. 1. (Color online) (a) Sheet resistance of the four different blanket metal stacks measured at various annealing temperatures. Cross-sectional TEM micrographs of the $\mathrm{TaN} / \mathrm{Cu} / \mathrm{Ta}$ structure: as-deposited (b), after annealing at $600^{\circ} \mathrm{C}(\mathrm{c})$ and $700{ }^{\circ} \mathrm{C}(\mathrm{d})$ for $60 \mathrm{~min}$. 
from the Ta layer through the $\mathrm{Cu}$ film to react with and transform the TaN on the other side of the $\mathrm{Cu}$ films to $\mathrm{Ta}_{1+\mathrm{x}} \mathrm{N}$. As can be inferred from the $R_{\mathrm{s}}$ data for the $\mathrm{Cu} / \mathrm{Ta}$ sample without any cap, ${ }^{4}$ segregation of the $\mathrm{Cu}$ GBs with the indiffused Ta can lead to an increase in $R_{\mathrm{S}}$ by about $10 \%$. Morphological evolutions with the layer stacks associated with the Ta diffusion may also cause $R_{\mathrm{s}}$ to increase in the asymmetric combinations; the cross-sectional STEM micrographs show clear changes with the layer structure at $600^{\circ} \mathrm{C}$, cf. Fig. 1(c), but severe ones at $700^{\circ} \mathrm{C}$, cf. Fig. 1(d), with reference to the as-deposited case, cf. Fig. 1(b). Grain growth in $\mathrm{Cu}$, causing the initial $R_{\mathrm{S}}$ drop, is clearly visible for the sample after annealing at $600^{\circ} \mathrm{C}$, in comparison with the asdeposited one. Such a grain growth was also observed in the symmetric combinations including both $\mathrm{TaN} / \mathrm{Cu} / \mathrm{TaN}$ and $\mathrm{Ta} / \mathrm{Cu} / \mathrm{Ta}$ (results not shown) as well as in $\mathrm{Cu}$ films without any cap. ${ }^{11}$ Apart from grain growth leading to a clearly discernable difference in grain structure, no other morphological change in the symmetric combination $\mathrm{TaN} / \mathrm{Cu} / \mathrm{TaN}$ could be concluded from RBS analysis even after annealing at $700-800{ }^{\circ} \mathrm{C}^{4}$ thus, this symmetric combination is especially interesting for the EM studies below.

\section{B. Characterization of EM test structures}

In the light of the above observations with respect to Ta diffusion and $R_{\mathrm{S}}$ variation, our choice of samples for EM studies below is confined to the symmetric $\mathrm{TaN} / \mathrm{Cu} / \mathrm{TaN}$ and asymmetric $\mathrm{TaN} / \mathrm{Cu} / \mathrm{Ta}$ metal stacks. Furthermore, in order to minimize possible grain growth effects during the EM studies, the samples were first annealed at $600^{\circ} \mathrm{C}$. In addition to grain growth, annealing at $600^{\circ} \mathrm{C}$ also causes Ta to diffuse through the $\mathrm{Cu}$ film toward the TaN cap in the asymmetric combination, ${ }^{4}$ thereby causing the TaN to change into $\mathrm{Ta}_{1+\mathrm{x}} \mathrm{N}^{4}$ Both $\mathrm{Cu}$ surfaces will thus be in touch with $\mathrm{Ta}-$ rich films. The reference structures, without the $600^{\circ} \mathrm{C}$ anneal, only received an unintentional $300^{\circ} \mathrm{C}$ heat treatment during the PECVD $\mathrm{SiN}_{\mathrm{x}}$ passivation, a temperature too low to expect measurable movement of $\mathrm{Ta}$ to occur in the $\mathrm{Cu}$ films. This allows us to isolate the effects of grain growth and Ta penetration on the resistance to EM.

In order to ascertain that a constant current density was attained for a sensible comparison, the actual line width was determined. This was achieved by examining the line resistance for 400 and $800 \mu \mathrm{m}$ long lines with intermediate potential sensing terminals. For each line length, seven different line widths from 2 to $20 \mu \mathrm{m}$ were included. The $\mathrm{Cu}$ film thickness was $300 \mathrm{~nm}$ in all cases. The measurements were carried out on all four samples at room temperature (RT) with a low current in order to avoid Joule heating. The results showed that the width deviation, $\Delta \mathrm{W}$, for the $\mathrm{TaN} / \mathrm{Cu} / \mathrm{Ta}$ and $\mathrm{TaN} /$ $\mathrm{Cu} / \mathrm{TaN}$ reference samples were $\Delta \mathrm{W}=-0.69$ and $-0.54 \mu \mathrm{m}$, respectively. For the TaN/Cu/Ta and $\mathrm{TaN} / \mathrm{Cu} / \mathrm{TaN} 600-{ }^{\circ} \mathrm{C}-$ annealed samples, the extrapolated $\Delta \mathrm{W}$ were -0.47 and $-0.83 \mu \mathrm{m}$, respectively.

The device-under-test itself was used to monitor the actual temperature during the EM stress testing caused by excessive Joule heating. ${ }^{12}$ The hot chuck was set at different temperatures ranging from RT up to $350^{\circ} \mathrm{C}$. At each temperature, a low current of $2 \mathrm{~mA}$ was applied, so as to avoid Joule heating, to the line structure and the resistance value was recorded. An external thermometer attached to the wafer surface and close to the structure was used for accurate temperature calibration. Typical resistance versus temperature curves for the investigated structures are depicted in Fig. 2. These calibration curves were later used to find the real temperature of the resistor lines during EM stress testing. The respective temperature coefficient and RT resistivity of the measured structures are recapitulated in Table I. The observed data are in close agreement with reported values. ${ }^{13}$

\section{Electromigration in $\mathrm{Cu}$ interconnects at elevated temperatures}

The good EM robustness of $\mathrm{Cu}$ interconnect necessitates highly accelerated tests to obtain the results within acceptable time frames. ${ }^{14}$ During the EM measurement, the current density was kept constant at $12 \mathrm{MA} / \mathrm{cm}^{2}$ (adjusted according to the measured line width deviations) while the chuck/substrate temperature was varied from 250 to $350^{\circ} \mathrm{C}$. The measurement started with a low current to first monitor the line resistance at a given temperature whereupon the current level was ramped up to the final stress level of $12 \mathrm{MA} / \mathrm{cm}^{2}$. The resulting line-resistance value, due to excessive heating, was recorded after a short stabilization period. This resistance value was compared with the calibration data and used to determine the actual stress temperature of the device. The stress was terminated when the line-resistance showed a $10 \%$ increase, since this was used as a failure criterion. ${ }^{15}$

At the current density of $12 \mathrm{MA} / \mathrm{cm}^{2}$, the $\mathrm{TaN} / \mathrm{Cu} / \mathrm{Ta}$ structure was found to be more robust than its $\mathrm{TaN} / \mathrm{Cu} / \mathrm{TaN}$ counterpart. For instance, the $\mathrm{TaN} / \mathrm{Cu} / \mathrm{Ta}$ structure measured at $30{ }^{\circ} \mathrm{C}$ could survive for about three times longer than a similar $\mathrm{TaN} / \mathrm{Cu} / \mathrm{TaN}$ structure. Two typical resistance-versustime traces at this temperature, one for $\mathrm{TaN} / \mathrm{Cu} / \mathrm{Ta}$ and one for $\mathrm{TaN} / \mathrm{Cu} / \mathrm{TaN}$, are shown as a linear-log plot in Fig. 3 for

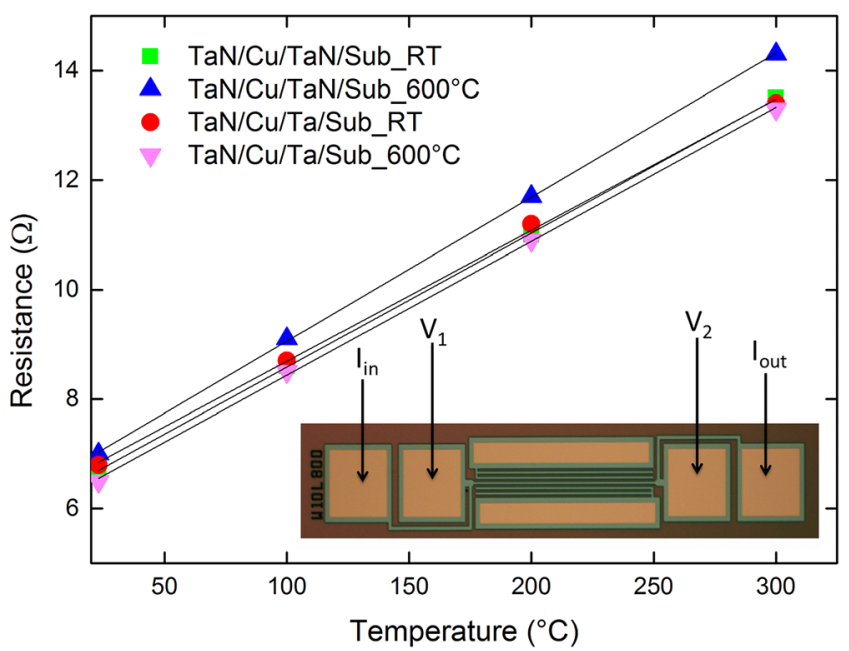

FIG. 2. (Color online) Temperature calibration curves with the extracted parameters in Table I, with the four-terminal measurement structure shown as inset. 
TABLE I. Temperature coefficient, $\alpha$, and RT resistance, $\mathrm{R}_{0}$, of the TaN/Cu/ $\mathrm{TaN}$ and $\mathrm{TaN} / \mathrm{Cu} / \mathrm{Ta}$ stacks for EM stressing studies, extracted in accordance to the definition $\left(\mathrm{R}-\mathrm{R}_{0}\right) / \mathrm{R}_{0}=\alpha \times\left(\mathrm{T}-\mathrm{T}_{0}\right)$ with $\mathrm{R}_{0}$ as the resistance at room temperature $T_{0}$.

\begin{tabular}{lcc}
\hline \hline Sample & $\begin{array}{c}\mathrm{RT} \text { resistance, } \\
\mathrm{R}_{0}(\Omega)\end{array}$ & $\begin{array}{c}\text { Temperature coefficient, } \\
\alpha\left(1 /{ }^{\circ} \mathrm{C}\right)\end{array}$ \\
\hline $\mathrm{TaN} / \mathrm{Cu} / \mathrm{TaN}, \mathrm{RT}$ & 6.7 & $3.7 \times 10^{-3}$ \\
$\mathrm{TaN} / \mathrm{Cu} / \mathrm{TaN}, 600^{\circ} \mathrm{C}$ & 7.0 & $3.8 \times 10^{-3}$ \\
$\mathrm{TaN} / \mathrm{Cu} / \mathrm{Ta}, \mathrm{RT}$ & 6.8 & $3.5 \times 10^{-3}$ \\
$\mathrm{TaN} / \mathrm{Cu} / \mathrm{Ta}, 600^{\circ} \mathrm{C}$ & 6.5 & $3.8 \times 10^{-3}$ \\
\hline \hline
\end{tabular}

comparison. The SEM micrographs of failed $\mathrm{TaN} / \mathrm{Cu} / \mathrm{Ta}$ and $\mathrm{TaN} / \mathrm{Cu} / \mathrm{TaN}$ lines are shown as insets.

The recorded data for the four investigated interconnect combinations, two references without intentional heat treatment and two after the $600{ }^{\circ} \mathrm{C}$ anneal, are depicted in Fig. 4 in the form of a lognormal plot of time-to-failure (TTF) characteristics. A linear fit to the curves in the graph gives the values for mean TTF (MTF) and lognormal sigma summarized in Table II. The improvement in EM endurance by the anneal at $600{ }^{\circ} \mathrm{C}$ can be explained by recourse to the
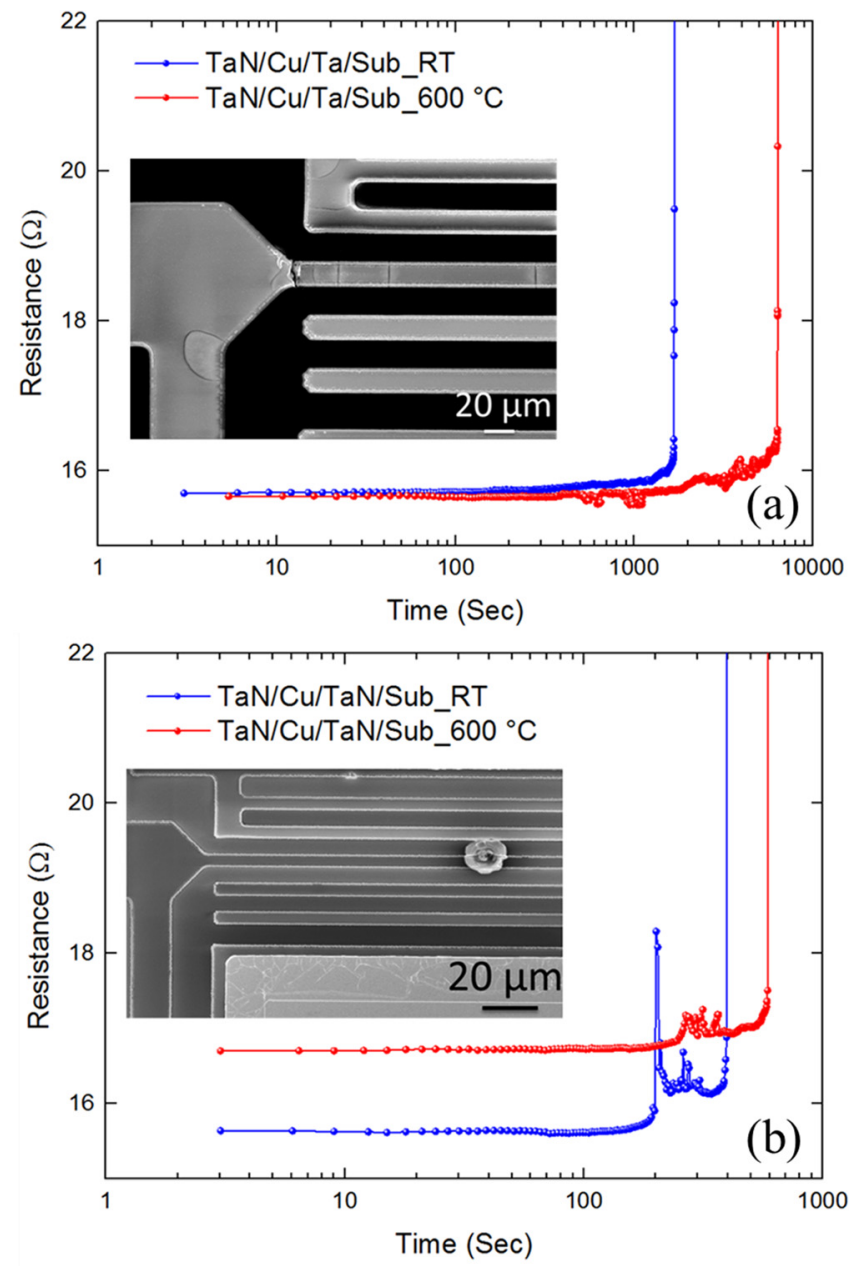

FIG. 3. (Color online) Representative resistance-vs-time traces for (a) TaN/Cu/ $\mathrm{Ta}$ and (b) $\mathrm{TaN} / \mathrm{Cu} / \mathrm{TaN}$ both measured at $300{ }^{\circ} \mathrm{C}$ with a $12 \mathrm{MA} / \mathrm{cm}^{2}$ current density, with the insets showing the failed lines for the RT cases. Note the 1 -order-of-magnitude difference in scale in the $\mathrm{x}$-axis between (a) and (b). current model for EM. ${ }^{16}$ Thus, for $\mathrm{Cu}$ at temperatures below half of the melting point, i.e., below about $400{ }^{\circ} \mathrm{C}$, the $\mathrm{Cu}$ atoms involved in the EM failure are transported along the surface where there is an ample supply of vacancies. These vacancies are more or less unperturbed by the presence of a surface layer of $\mathrm{TaN}$ since the interaction between $\mathrm{TaN}$ and $\mathrm{Cu}$ is rather weak, as attested to by adhesion and wetting experiments on such interfaces. ${ }^{17,18}$ In fact, the adhesion strength between $\mathrm{TaN}_{\mathrm{x}}$ and $\mathrm{Cu}$ has been found to decrease with increasing nitrogen concentration. ${ }^{19}$ When the temperature is increased to $600^{\circ} \mathrm{C}$, the thermal energy is large enough to allow for a rapid rearrangement of the atoms and vacancies at the TaN/Cu interface. Although too small to be detectable by RBS, even after an $800^{\circ} \mathrm{C}$ anneal, ${ }^{4}$ it is also likely that the reactively sputter-deposited $\mathrm{TaN}$ layer is not exactly stoichiometric and will emit a small amount of Ta atoms. Tantalum is known to interact with a $\mathrm{Cu}$ surface 20,21 and can, therefore, be expected to interfere with the rearrangement of atoms at the $\mathrm{Cu} / \mathrm{TaN}$ interface.

When larger amounts of $\mathrm{Ta}$ are present, as is the case at the $\mathrm{Cu} / \mathrm{Ta}$ and $\mathrm{Cu} / \mathrm{Ta}_{1+x} \mathrm{~N}$ interfaces, the interaction is so strong that a very thin layer of amorphous $\mathrm{Ta}-\mathrm{Cu}$ is formed. ${ }^{20-22}$ Such a strong interaction will effectively block surface diffusion at the $\mathrm{Cu} / \mathrm{Ta}$ interface. This interaction is probably initiated during the PECVD $\mathrm{SiN}_{\mathrm{x}}$ step at $300^{\circ} \mathrm{C}$ and is reflected already at RT in the form of the significantly improved EM resistance of the $\mathrm{TaN} / \mathrm{Cu} / \mathrm{Ta}$ interconnect without intentional heat treatment, as shown in Figs. 3 and 4. At $600^{\circ} \mathrm{C}$ where the annealing was performed, the amorphization or $\mathrm{Ta}-\mathrm{Cu}$ interaction at the $\mathrm{Cu} / \mathrm{Ta}$ interface is fully developed. ${ }^{11,20}$ As we have observed earlier, ${ }^{4,5,11}$ the liberated $\mathrm{Ta}$ atoms will diffuse through the $\mathrm{Cu}$ film via the GBs in amounts readily detectable by RBS. In $\mathrm{Cu}, \mathrm{GB}$ diffusion starts around half the melting point, i.e., around $400^{\circ} \mathrm{C}$. When at the $\mathrm{Cu} / \mathrm{TaN}$ interface, these $\mathrm{Ta}$ atoms will strive to convert the $\mathrm{TaN}$ layer toward $\mathrm{Ta}_{2} \mathrm{~N}$ at

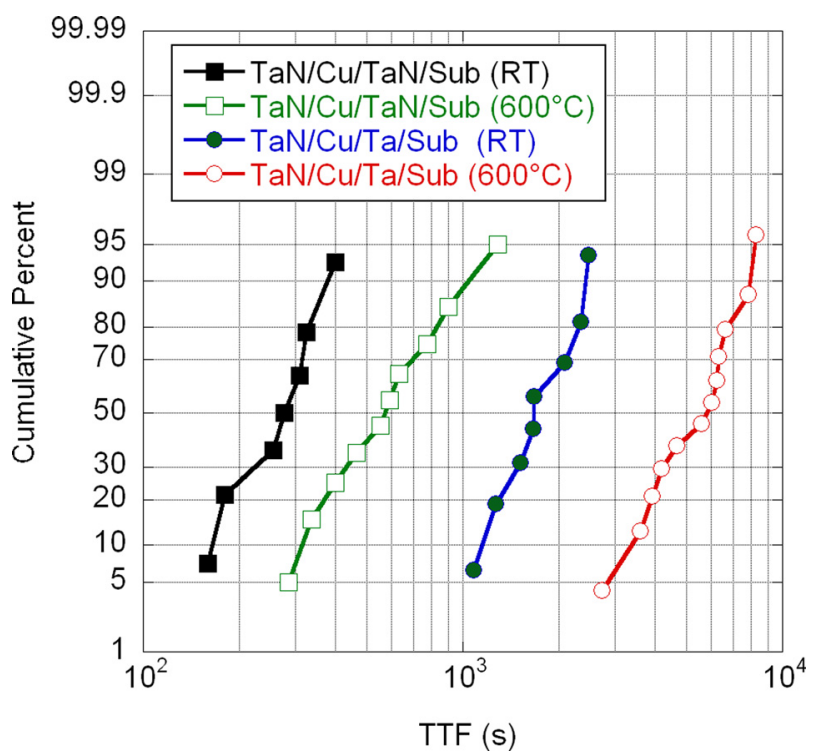

FIG. 4. (Color online) Plot of cumulative TTF for the four cases with TaN/ $\mathrm{Cu} / \mathrm{TaN}$ as-prepared, $\mathrm{TaN} / \mathrm{Cu} / \mathrm{TaN} 600{ }^{\circ} \mathrm{C}$ anneal, $\mathrm{TaN} / \mathrm{Cu} / \mathrm{Ta}$ as-prepared, and $\mathrm{TaN} / \mathrm{Cu} / \mathrm{Ta} 600^{\circ} \mathrm{C}$ anneal. 
TABLE II. MTF, lognormal sigma, and $E_{\mathrm{a}}$ for the four samples (Cu $5 \mu \mathrm{m}$ width, $400 \mu \mathrm{m}$ length, and $300 \mathrm{~nm}$ thickness) undergone the EM testing.

\begin{tabular}{lccc}
\hline \hline Sample & MTF $(\mathrm{s})$ & Lognormal sigma & $E_{\mathrm{a}}(\mathrm{eV})$ \\
\hline $\mathrm{TaN} / \mathrm{Cu} / \mathrm{TaN}, \mathrm{RT}$ & $3.1 \times 10^{2}$ & 0.13 & - \\
$\mathrm{TaN} / \mathrm{Cu} / \mathrm{TaN}, 600^{\circ} \mathrm{C}$ & $5.7 \times 10^{2}$ & 0.15 & 0.47 \\
$\mathrm{TaN} / \mathrm{Cu} / \mathrm{Ta}, \mathrm{RT}$ & $1.7 \times 10^{3}$ & 0.25 & - \\
$\mathrm{TaN} / \mathrm{Cu} / \mathrm{Ta}, 600^{\circ} \mathrm{C}$ & $5.3 \times 10^{3}$ & 0.20 & 1.0 \\
\hline \hline
\end{tabular}

the interface, detected as $\mathrm{Ta}_{1+\mathrm{x}} \mathrm{N}$ in Figs. 1(c) and 1(d). This enhanced interfacial interaction can slow down the interfacial atomic movement, thereby providing additional EM resistance, which is clearly observed in Figs. 3 and 4.

In order to shed more light on the importance of the $\mathrm{Cu} /$ $\mathrm{TaN}$ and $\mathrm{Cu} / \mathrm{Ta}$ interfaces, we have determined the TTF activation energy, $E_{\mathrm{a}}$, appropriate to the temperature range $200-400{ }^{\circ} \mathrm{C}$ for the two annealed cases. This was performed on $\mathrm{Cu}$ conductors that were $5 \mu \mathrm{m}$ wide, $400 \mu \mathrm{m}$ long, and $300 \mathrm{~nm}$ thick. The results for this configuration are given in Table II. Although we have not been able to find any published results for our particular layered geometry, our result for $\mathrm{TaN} / \mathrm{Cu} / \mathrm{Ta}$ is in accordance with published results for damascene structures, which are around $0.9 \mathrm{eV} .{ }^{14}$ However, it should be kept in mind that in such structures the $\mathrm{Cu}$ conductor is surrounded on three sides by a Ta liner, whereas only one side faces Ta in our geometry. An activation energy of $1.4 \mathrm{eV}$ for damascene $\mathrm{Cu}$ conductors in contact with $\mathrm{Ta}$ on all four sides is also available in the literature. ${ }^{10}$ The activation energy for $\mathrm{TaN} / \mathrm{Cu} / \mathrm{TaN}$ is remarkably low, on the other hand. We have not been able to find any result for similar configurations in the literature. It should be kept in mind, though, that the fact that there are not only one, but two weakly interacting $\mathrm{Cu} / \mathrm{TaN}$ interfaces in itself will lower the activation energy for the overall EM process, by referring to the discussion above.

\section{CONCLUSIONS}

We have investigated the high-temperature behavior of four different $\mathrm{Cu}$-based interconnect schemes with $\mathrm{Ta}$ or $\mathrm{TaN}$ as the cap and/or barrier. Electrically and morphologically similar, the $\mathrm{TaN} / \mathrm{Cu} / \mathrm{Ta}$ stack seems to have a better electromigration performance with higher activation energy and longer lifetime than its $\mathrm{TaN} / \mathrm{Cu} / \mathrm{TaN}$ counterpart.
Interfacial characteristics in term of atomic interaction and diffusion are discussed as the root cause for this difference.

\section{ACKNOWLEDGMENTS}

The authors would like to acknowledge Mats Hagberg, John Halonen, and Niclas Lindvall at Chalmers University of Technology for assistance in metal etching. This work was partially supported by the Swedish Foundation for Strategic Research (Nos. RE10-0011 and RIF-14-0053).

${ }^{1}$ S. Venkatesan et al., Technical Digest of International Electron Devices Meeting (IEDM) (1997), pp. 769-772.

${ }^{2}$ D. Edelstein et al., Technical Digest of International Electron Devices Meeting (IEDM) (1997), pp. 773-776.

${ }^{3}$ J. R. Lloyd and J. J. Clement, Thin Solid Films 262, 135 (1995).

${ }^{4}$ S. Mardani, H. Norström, U. Smith, J. Olsson, and S.-L. Zhang, Microelectron. Eng. 137, 37 (2015).

${ }^{5}$ S. Mardani, H. Norström, U. Smith, and S.-L. Zhang, J. Vac. Sci. Technol., B 34, 040606 (2016).

${ }^{6} \mathrm{~S}$. Mardani, "Copper and silver metallization for high temperature applications," Ph.D. dissertation (The Faculty of Science and Technology, 2016), p. 41.

${ }^{7}$ O. Aubel, W. Hasse, M. Hommel, and H. Koerner, Microelectron. Eng. 82, 600 (2005).

${ }^{8}$ R. Rosenberg, D. C. Edelstein, C.-K. Hu, and K. P. Rodbell, Annu. Rev. Mater. Sci. 30, 229 (2000).

${ }^{9}$ A. von Glasow et al., 41 st Annual International Reliability Physics Symposium, Dallas, TX (2003), pp. 146-150.

${ }^{10}$ C.-K. Hu, L. Gignac, E. Liniger, B. Herbst, D. L. Rath, S. T. Chen, S. Kaldor, A. Simon, and W.-T. Tseng, Appl. Phys. Lett. 83, 869 (2003).

${ }^{11}$ S. Mardani, H. Norström, F. Gustavsson, T. Nyberg, D. Primetzhofer, K. Leifer, D. Wu, and S.-L. Zhang, "Massive Ta diffusion observed in $\mathrm{Cu}$ thin films but not in Ag counterparts," J. Vac. Sci. Technol. B (submitted).

${ }^{12}$ J. von Hagen and H. A. Schafft, IEEE International Integrated Reliability Workshop Final Report, Lake Tahoe, CA, 21-24 October (2002), pp. 45-49.

${ }^{13}$ B.-S. Chiou, J.-S. Jiang, H.-W. Wang, and H.-Y. Hung, Proceedings of the 50th Electronic Components and Technology Conference, Las Vegas, NV, 21-24 May (2000), pp. 1686-1689.

${ }^{14}$ O. Aubel, W. Hasse, and M. Hommel, IEEE Trans. Device Mater. Reliab. 3, 213 (2003).

${ }^{15}$ J. von Hagen, R. Bauer, S. Penka, A. Pietsch, W. Walter, and A. Zitzelsberger, IEEE International Integrated Reliability Workshop Final Report, Lake Tahoe, CA, 21-24 October (2002), pp. 41-44.

${ }^{16}$ K. N. Tu, J. Appl. Phys. 94, 5451 (2003).

${ }^{17}$ O. van der Straten, Y. Zhu, J. Rullan, K. Dunn, and A. E. Kaloyerosa, J. Mater. Res. 21, 255 (2006).

${ }^{18}$ T. Vanypre, M. Cordeau, T. Mourier, W. F. A. Besling, J.-C. Dupuy, and J. Torres, Microelectron. Eng. 83, 2373 (2006).

${ }^{19}$ A. Sekiguchi and J. Koike, Jpn. J. Appl. Phys., Part 1 47, 1042 (2008).

${ }^{20}$ K.-W. Kwon, H.-J. Lee, and R. Sinclair, Appl. Phys. Lett. 75, 935 (1999).

${ }^{21}$ P. Heino and E. Ristolainen, J. Vac. Sci. Technol., B 20, 2052 (2002).

${ }^{22}$ H.-R. Gong and B.-X. Liu, Appl. Phys. Lett. 83, 4515 (2003). 